\title{
Survival and Inoculum Production of Gibberella zeae in Wheat Residue
}

\author{
S. A. Pereyra and R. Dill-Macky, Department of Plant Pathology, University of Minnesota, St. Paul 55108; and \\ A. L. Sims, Department of Soil, Water and Climate, University of Minnesota, Northwest Research and Outreach \\ Center, Crookston 56176
}

\begin{abstract}
Pereyra, S. A., Dill-Macky, R., and Sims, A. L. 2004. Survival and inoculum production of Gibberella zeae in wheat residue. Plant Dis. 88:724-730.

Survival and inoculum production of Gibberella zeae (Schwein.) Petch (anamorph Fusarium graminearum (Schwabe)), the causal agent of Fusarium head blight of wheat and barley, was related to the rate of wheat (Triticum aestivum L.) residue decomposition. Infested wheat residue, comprising intact nodes, internodes, and leaf sheaths, was placed in fiberglass mesh bags on the soil surface and at 7.5- to $10-\mathrm{cm}$ and 15- to 20-cm depths in chisel-plowed plots and 15 to 20 $\mathrm{cm}$ deep in moldboard-plowed plots in October 1997. Residue was sampled monthly from April through November during 1998 and every 2 months through April to October 1999. Buried residue decomposed faster than residue placed on the soil surface. Less than $2 \%$ of the dry-matter residue remained in buried treatments after 24 months in the field, while $25 \%$ of the residue remained in the soil-surface treatment. Survival of G. zeae on node tissues was inversely related to the residue decomposition rate. Surface residue provided a substrate for G. zeae for a longer period of time than buried residue. Twenty-four months after the initiation of the trial, the level of colonization of nodes in buried residue was half the level of colonization of residue on the soil surface. Colonization of node tissues by G. zeae decreased over time, but increased for other Fusarium spp. Ascospores of G. zeae were still produced on residue pieces after 23 months, and these spores were capable of inducing disease. Data from this research may assist in developing effective management strategies for residues infested with G. zeae.
\end{abstract}

Fusarium head blight (FHB or scab), is an important disease of wheat and barley worldwide $(27,43)$. The disease has become a major problem in the United States over the past decade, resulting in devastating losses to growers. FHB causes significant reductions of grain yield and quality, partly through the production of mycotoxins, especially trichothecenes, that are toxic to both humans and animals (4). Some of the proposed causes for the increase in FHB in the United States have been wet weather, particularly at and after anthesis, the widespread use of susceptible wheat cultivars, and a nationwide increase in conservation tillage practices $(11,28)$.

The main pathogen associated with FHB in the Upper Midwest of the United States is Fusarium graminearum (Schwabe) (teleomorph Gibberella zeae (Schwein.) Petch; 44). F. graminearum survives saprophytically on crop residues such as corn, small grain cereals $(39,42,43,45)$, and nu-

Corresponding author: R. Dill-Macky

E-mail: ruthdm@umn.edu

Current address of S. A. Pereyra: Instituto Nacional de Investigacion Agropecuaria (National Institute for Agricultural Research), INIA La Estanzuela, Ruta 50 km 11, 70000, Colonia, Uruguay.

Accepted for publication 10 March 2004.

Publication no. D-2004-0510-02R

(C) 2004 The American Phytopathological Society merous grasses (37). Ascospores released from perithecia in crop residues located on the soil surface represent the primary inoculum for the disease (39). In the northern regions of North America, perithecia form during late spring or early summer and ejected ascospores can be deposited on wheat spikes at flowering $(2,14,36)$.

FHB management practices include crop rotation with nonsusceptible hosts and incorporation of infested crop residues $(19,20,27,43)$. Effective crop rotations provide sufficient time for the pathogen population to decrease in the absence of a host $(9,40)$. Rotations away from corn, wheat, and barley have been shown to reduce FHB levels in subsequent wheat crops $(12,35,39)$. Soil incorporation of residue promotes straw decomposition and reduces primary inoculum $(4,10,35,39)$ by preventing inoculum development and dispersal (22).

In the United States, legislation mandates that growers retain at least $30 \%$ of residue cover at crop emergence on land classified as prone to soil erosion (3). In the Red River Valley of Minnesota, North Dakota, South Dakota, and the Canadian province of Manitoba, a significant increase in conservation tillage practices in the last 20 years has resulted in greater amounts of crop residues on the soil surface (28). The adoption of reduced-tillage systems has raised concerns over the role of crop residues in the FHB epidemics that devastated this region during the 1990s.
Research on the long-term survival of $G$. zeae in association with wheat residue is scarce (22). In order to establish appropriate cultural practices for the management of FHB, further studies are needed to understand the role of crop residues in the survival and production of inoculum of $G$. zeae.

The objective of this study was to determine the relationship between the decomposition of residues from spring wheat crops and the survival and inoculum production of $G$. zeae and thus facilitate the development of management strategies for Fusarium-infested residues.

\section{MATERIALS AND METHODS}

Residue of the hard red spring wheat cv. Russ from a commercial wheat crop was used to determine the survival and ascospore production of G. zeae. Stem sections $24 \mathrm{~cm}$ long, consisting of nodes, internodes, and leaf sheaths, were arbitrarily selected and placed in 15-by-45-cm fiberglass mesh (1- to 1.5 -mm openings) bags. Each bag contained $20 \mathrm{~g}$ of residue (approximately 60 to 70 pieces), equivalent to $2,857 \mathrm{~kg}$ of residue per hectare based on the surface area of the bag. Six hundred bags were used in the study. The residue was highly infested with G. zeae (96\% of nodes were colonized) at the time the experiment was initiated.

Treatments were established for studies of residue decomposition and G. zeae survival and ascospore production. Bags of residue were placed in the field in October 1997 at the Northwest Research and Outreach Center, Crookston, $\mathrm{MN}$, in a Wheatville very fine sandy loam soil (coarse silty over clayey, frigid aeric calciquoll, 3 to $3.5 \%$ organic matter, $\mathrm{pH} 8$, with 0 to $2 \%$ slope) at various depths in two tillage treatments. The experimental design was an incomplete split plot with five replications, where the main plots were the tillage treatments (chisel plow and moldboard plow) and the subplots were different residue placement depths (surface, 7.5 to 10 $\mathrm{cm}$, and 15 to $20 \mathrm{~cm}$ ).

Prior to implementing the tillage treatments, the previous wheat crop residue was clipped by a forage harvester 4 to 6 $\mathrm{cm}$ from the soil surface, blown into a trailer, and removed from the plot area. Chisel-plow treatments were plowed in the fall using a John Deere chisel plow (model 100, 3.7-m-wide plow with 7.5-cm-wide chisel points with twisted spikes and a 30$\mathrm{cm}$ shank spacing; Deere and Company, 
Moline, IL). The plow depth was $20 \mathrm{~cm}$ and bags were placed in the furrow made by the chisel. Plots were placed at $1.5-\mathrm{m}$ centers, parallel to the direction of plowing. In each plot, subplots were at three soil depths: soil surface (CPS), 7.5 to 10 cm (CP7.5), and 15 to $20 \mathrm{~cm}$ (CP15). Subplots within each plot were placed $45 \mathrm{~cm}$ apart. In the moldboard-plow treatments, a moldboard plow (Case International, East Moline, IL), with five bottom tines spaced at $36.6-\mathrm{cm}$ centers, was used to make furrows 15 to $20 \mathrm{~cm}$ deep. Bags (MP15) were placed individually at $1.5-\mathrm{m}$ intervals (15 bags per strip) at a depth of 15 to $20 \mathrm{~cm}$ in the furrow, then buried with a subsequent pass of the plow. Each bag contained a plastic vial with an identification number for future collection. The locations where bags were buried were marked with plastic flags. Nitrogen fertilizer was broadcast on the surface of all plots at $67 \mathrm{~kg} \mathrm{ha}^{-1}$ as $\mathrm{NH}_{4} \mathrm{NO}_{3}$, following both the tillage operations and placement of residue.

Air temperature, rainfall, and relative humidity data were collected by a weather station at the site throughout the experiment. Soil moisture and temperature were monitored from April 1998 through the duration of the experiment using a CR23X micrologger with CS615-L soil moisture sensors and 107-L soil temperature sensors (Campbell Scientific, Logan, UT). Moisture was not recorded on the soil surface (CPS). Temperature and moisture were monitored at four locations within the plot site; two in the chisel-plowed treatments and two in the moldboard-plowed treatments. Soil temperature sensors were placed 4,10 , and $20 \mathrm{~cm}$ below the soil surface, and moisture sensors were placed at 10 and $20 \mathrm{~cm}$.

Two bags of residue were collected from each replicate of each treatment (CPS, CP7.5, CP15, and MP15) at every sampling time (collection dates were 21 April, 20 May, 16 June, 15 July, 11 August, 8 September, 8 October, and 3 November 1998; 28 April, 26 May, 7 July, 25 August, and 20 October 1999; and 26 April and 11 August 2000). The bags collected at each sampling period were arbitrarily divided into two sets, each consisting of 20 bags composed of one bag of each treatment per replicate. The last two sampling dates (2000) were not included in the statistical analysis due to the small amount of residue recovered. Following the recovery of residue samples, the samples from one set were evaluated for residue decomposition and residue biochemical composition, and the samples from the second set were evaluated for G. zeae survival and ascospore production.

The set of residue bags collected to evaluate residue decomposition and residue biochemical composition were washed, in the bags, with tap water to remove adhered soil, dried at $25^{\circ} \mathrm{C}$ for $24 \mathrm{~h}$, and washed again with tap water for ap- proximately $30 \mathrm{~s}$ and dried at $60^{\circ} \mathrm{C}$ for approximately $48 \mathrm{~h}$ until no further weight change was observed. Residue then was removed from the bags and weighed. Residue decomposition was expressed as dry matter loss based on the $20 \mathrm{~g}$ of residue initially placed in the bag. Biochemical composition of the residue was determined by gravimetric procedures according to Harper and Lynch (17). Biochemical components determined were soluble components, hemicellulose, cellulose, lignin, and ash content.

The second set of residue bags was used to evaluate survival of $G$. zeae and ascospore production. Bags were manually shaken to remove loose soil and air dried at $25^{\circ} \mathrm{C}$ for approximately $24 \mathrm{~h}$. Thirty nodes were arbitrarily selected from each bag and excised from the stem tissue. Each excised node consisted of a $1.5-\mathrm{cm}-$ long stem piece including a single node. Nodes were sampled because they represent the structures most resistant to decomposition. The nodes were surface disinfected in a $0.5 \%$ sodium hypochlorite solution for $1 \mathrm{~min}$, rinsed three times in sterile distilled water, and blotted dry on sterile filter paper. Nodes were placed on pentachloronitrobenzene (PCNB) agar medium (15 $\mathrm{g}$ of peptone, $1 \mathrm{~g}$ of $\mathrm{KH}_{2} \mathrm{PO}_{4}, 0.5 \mathrm{~g}$ of $\mathrm{MgSO}_{4}$, $1 \mathrm{~g}$ of Terraclor [75\% PCNB, wt/wt], $15 \mathrm{~g}$ of agar, $0.24 \mathrm{~g}$ of neomycin sulfate, and 1 $\mathrm{g}$ of streptomycin sulfate per liter of deionized water) (30) in 9-cm-diameter plastic petri dishes (10 nodes per plate and three plates per sample) and incubated at 20 to $22^{\circ} \mathrm{C}$ with 12 -h light and dark cycles provided by a $1: 1$ combination of cool-white (F40/CWX/CVP; Sylvania, St. Marys, PA) and blacklight (UVA, F40BL; GE lighting, Fairfield, CT) fluorescent lights for 7 days. Colonies growing with salmon to pinkwhite mycelium were recorded as Fusarium spp. G. zeae colonies were determined by transferring 10 arbitrarily selected Fusarium spp. colonies per sample (50 colonies per treatment) to carnation leaf-piece agar (CLA) medium (three to five sterile carnation leaf pieces [ 5 to $7 \mathrm{~mm}$ in diameter] per $2 \mathrm{ml}$ of $1.5 \%$ water agar) (15) and potato dextrose agar (PDA). Cultures were incubated at 20 to $22^{\circ} \mathrm{C}$ with 12-h light and dark cycles for 10 days. Bluish to black perithecia formation indicated the presence of $G$. zeae isolates. Fusarium colonies not forming perithecia were identified to species according to the procedures of Nelson et al. (31) and Burgess et al. (8).

Ascospore production of $G$. zeae was determined on residue sampled on 21 April, 20 May, 15 July, 8 September, and 3 November 1998 and 28 April, 26 May, 7 July, 25 August, and 20 October 1999. Testing ascospore production at all dates was not possible due to limited resources. In 1998 (April, May, July, and September samples), 24 nodes obtained from the residue of each sample were surface disin- fected with $0.5 \%$ sodium hypochlorite for $1 \mathrm{~min}$, rinsed three times in distilled water, and placed on the surface of sterile sand $(150 \mathrm{~g})$ moistened with sterile distilled water $(20 \mathrm{~g})$ in polycarbonate tissue-culture boxes (109 by 109 by $96 \mathrm{~mm}$, model 700-534; LifeGuard, Rehovot, Israel) fitted with polycarbonate microporous vented lids to prevent water condensation (model 750-547; LifeGuard). Eight nodes were placed on the sand surface in each box with three boxes per sample. To facilitate the development of mature perithecia, nodes were incubated at 20 to $22^{\circ} \mathrm{C}$ under 12-h light and dark cycles for 21 days, which had been identified as the appropriate time for perithecia and mature ascospore production under optimal environmental conditions (37). Gross box weight was checked every 4 to 5 days and sterile distilled water was added as necessary to maintain the original weight. Following the 21 day incubation, a microscope slide (2 by $6.9 \mathrm{~cm}$ ), coated on one side with a thin layer of silicone grease (Sampling Technologies Inc., Minnetonka, MN) was suspended in each box $2 \mathrm{~cm}$ above the residue for $24 \mathrm{~h}$ with the greased side down. The slides then were removed from the boxes and stored at $4{ }^{\circ} \mathrm{C}$ until evaluated. Ascospores on each slide were counted and the number of ascospores per square centimeter was calculated.

Due to the reduction in the number of nodes recovered in November 1998 and subsequent sampling times, as well as high variability (within-treatment error) obtained in the 1998 results, a different procedure was used for determining ascospore production after September 1998. A uniform weight of nodes $(1.5-\mathrm{cm}$-long stem pieces, each including a single node) was examined from each treatment at a given sampling time. The weight of nodes was determined by the limiting treatment (containing the least recovered node tissue) for a given sampling date. Nodes were surface disinfected and incubated on sterile sand media as described previously. Nodes with mature perithecia were placed in a solution of sterile distilled water and polyoxyethylene 20-sorbitan monolaurate (Tween 20; Fisher Scientific, Fair Lawn, NJ). The dilution ratio used was $1 \mathrm{~g}$ of residue to 20 $\mathrm{ml}$ of water to 1 drop of Tween 20 . Nodes were left in the solution for $10 \mathrm{~h}$ to allow ascospore discharge and then vigorously shaken for $10 \mathrm{~min}$. Three aliquots of 1.0 $\mathrm{ml}$ of the wash solution were obtained from each treatment and ascospore concentration was determined by counting ascospores in a known volume $(0.03 \mathrm{ml})$ of the suspension. Spores were counted under a compound microscope and expressed as ascospore number per gram of residue.

A pathogenicity test was conducted with eight isolates of $G$. zeae recovered in the August 1999 sampling in order to determine the ability of the ascospores recovered from cultures to induce disease in 
wheat spikes. Ascospores of G. zeae were obtained from cultures on CLA. Two isolates were recovered from each of the chisel-plowed treatments (surface, 7.5- to 10-cm depth, and 15- to 20-cm depth) and the moldboard-plowed treatment. Ascospores from isolate Butte86/ADA-11, which was characterized by Evans et al. (13) as being pathogenic, were used as a control. A noninoculated control treated with sterile distilled water also was examined.

Pathogenicity tests were conducted on the FHB-susceptible wheat cv. Norm. Two plants were grown in 13-cm-diameter clay pot in a soilless potting mix (Metromix 200; Scotts, Marysville, OH) in the greenhouse. Plants were maintained at 20 to $25^{\circ} \mathrm{C}$ with alternating 12-h light and dark periods. The plants were fertilized with 1818-18 N-P-K (Osmocote; Scotts) at the three- to four-leaf stage. Plants were inoculated immediately after anthesis (Feekes growth stage 10.5) (25). Two spikes per pot (replicate) and five replicates per isolate were point inoculated with $0.01 \mathrm{ml}$ of inoculum suspension $\left(2.5 \times 10^{4}\right.$ ascospores $/ \mathrm{ml}$ ). The inoculum was placed inside a spikelet, centrally located on the spike, with a microsyringe (Hamilton model 80830 attached to a Hamilton PB600 repeating dispenser model 83700; Hamilton Co., Reno, NV), without puncturing floret tissues. Plants were incubated in a dew chamber at 20 to $22^{\circ} \mathrm{C}$ with 12 -h photoperiod and $100 \%$ relative humidity for $72 \mathrm{~h}$. Plants then were returned to the greenhouse bench. Disease severity was

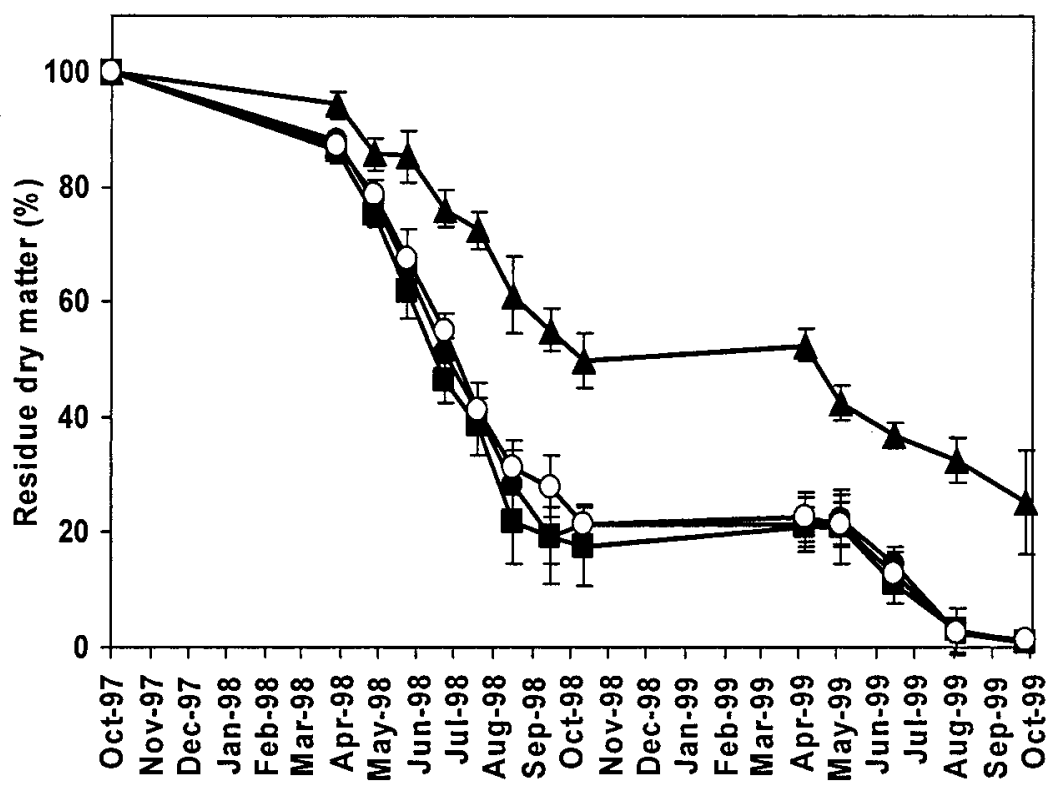

Time (months)

Fig. 1. Dry matter of wheat residue recovered from four tillage and residue placement treatments expressed as a percentage of the original sample $(\boldsymbol{\Lambda}$, chisel plow with residue on the soil surface; $\boldsymbol{\square}$, chisel plow with residue buried at $7.5 \mathrm{~cm}$;, chisel plow with residue buried at $15 \mathrm{~cm}$; and $\bigcirc$, moldboard plow with residue buried at $15 \mathrm{~cm}$ ) over 24 months. Residue was placed in the field in October 1997. Values represent means of five replicates. Vertical bars represent standard deviations of the means. evaluated 14 days after inoculation and expressed as the percentage of symptomatic spikelets per spike.

Residue decomposition, survival of $G$. zeae, ascospore production, and pathogenicity data were subjected to analyses of variance (Proc. GLM). Where the $F$ test was significant, the treatments means were compared using least significant differences (LSD) at $P=0.05$ (SAS Institute, percentage of nodes colonized by G. zeae and duration of exposure in the field for the periods characterizing the distinct seasons in Minnesota each year (April to July, July to October, and October to April) was tested by linear regression analysis (SAS Institute; 38). Relationships between residue decomposition and survival data and survival and ascospore production data were tested using Pearson correlation coefficients (Statistix, Tallahassee, FL; 1).

\section{RESULTS}

Mean soil temperatures from July to September 1998 and October to December 1998 were 21.6 and $5.8^{\circ} \mathrm{C}$, respectively. The mean soil temperature from April to June 1999 was $9.2^{\circ} \mathrm{C}$ and from July to September 1999 was $19.8^{\circ} \mathrm{C}$. Variations in soil temperatures near the soil surface were more extreme than at 7.5 and $15 \mathrm{~cm}$ deep (data not presented).

Mean soil moisture from June 1998 to September 1998 was $0.29 \mathrm{ml} \mathrm{cm}^{-3}$. Soil moisture was not recorded from early November to mid-March, when the soil was frozen. Mean soil moisture from April Cary, NC; 38). The relationship between
1999 to June 1999 and July 1999 to October 1999 was 0.30 and $0.33 \mathrm{ml} \mathrm{cm}^{-3}$, respectively. The high soil moisture in spring and summer was coincident with the precipitation registered at this time of the year. Soil moisture generally was greater in MP15 compared with CP7.5 and CP15.

The dry weight of wheat residue was significantly reduced in all treatments over the 24 months when samples were recovered. Residue decomposed faster in the first year (October 1997 to October 1998) compared with the second year (October 1998 to October 1999) (Fig. 1). For all treatments, remaining dry matter averaged $30.5 \%$ in October 1998 and $7.1 \%$ in October 1999. During the spring and summer months, residue generally decomposed faster, especially in the first year, than in the winter months, when residue decomposition was minimal (Fig. 1).

The percentage of dry matter of residue on the soil surface and buried residue were significantly different $(P=0.001)$ for individual sampling times. Buried residue (treatments CP7.5, CP15, and MP15) decomposed more quickly and completely (Fig. 1). Surface residue decomposition was more moderate and nodes were recovered at the end of the sampling period (April 2000). Of the residue studied, 99\% decomposed by October 1999, 24 months after the burial of residue, but only $75 \%$ of the residue on the soil surface had decomposed by the same time. Complete visual decomposition of buried residue occurred by April 2000, while complete decomposition of residue on the soil surface occurred by August 2000 (data not presented). Decomposition rates between plots chisel plowed at the $15-$ to $20-\mathrm{cm}$ depth and moldboard-plowed plots were significantly different only at the July 1998, September 1998, and October 1998 sampling dates.

Chemical composition (soluble components, lignin, hemicellulose, cellulose, and ash) changed as the residue decomposed. All components fluctuated more in residue on the soil surface (CPS) than in the buried residue (CP7.5, CP15, and MP15). The percentage of soluble components in the residue on the soil surface increased significantly $(P=0.0001)$ from $9.9 \%$ at the beginning of the sampling period (April $1998)$ to $11.8 \%$ at the end of the sampling period (October 1999). Soluble components of all buried residue treatments decreased significantly $(P=0.0001)$ over 24 months from 10.1 to $7.5,9.3$ to 7.4 , and 8.6 to $7.1 \%$ in CP7.5, CP15, and MP15, respectively. At the initial sampling times (April and May 1998), residue across all treatments contained a greater proportion of hemicellulose and cellulose compared with other components (soluble components, lignin, and ash). Hemicellulose content significantly decreased $(P=0.0001)$ in CPS from 29.3 to $15.8 \%$ over the 24 months of the study. Hemicellulose content decreased significantly, from 28.8 to 
$23.8 \%$ in CP7.5 $(P=0.0001), 29.4$ to $23.8 \%$ in $\mathrm{CP} 15(P=0.05)$, and 29.7 to $24.9 \%$ in MP15 $(P=0.001)$. Cellulose content decreased significantly $(P=$ 0.0001 ) in the CPS treatment, by $22.5 \%$ over 24 months. Cellulose content decreased significantly $(P=0.0001)$ in CP7.5 (7.5\%) and in CP15 (9.3\%) over the 24 months. There was no significant change in the cellulose content in the MP15 treatment. The percentage of lignin increased significantly $(P=0.0001)$ over time in each treatment. The increase in lignin content of residue on the soil surface was less than that in other treatments. Twenty-four months after trial initiation, lignin was the predominant component of the residue in all treatments, except in CPS, where ash (36.7\%) was the principal component.

During 2 years of sampling, G. zeae was isolated from wheat residue at all sampling times from all treatments (Fig. 2). Recovery of G. zeae from nodes of wheat residue decreased over time. Colonization of residue by $G$. zeae was significantly reduced $(P=0.001)$ after residue had been buried in the field for 8 months. The percentage of nodes colonized by $G$. zeae decreased most rapidly between the months of May and August in both years (Fig. 2).

Colonization of the residue by $G$. zeae was significantly $(P=0.001)$ influenced by burial of residue. Twenty-four months after the initiation of the trial (October 1999), nodes from the soil surface treatment had twice the colonization level (38.5\%) of buried nodes (15.6 to $18.2 \%$ ). In April $2000,23 \%$ of the nodes from the soil surface treatment were still colonized by $G$. zeae (data not presented).

Analysis of the relationship between the percentage of colonized nodes and the duration of exposure in the field indicated that the rate of decline for nodes infected with $G$. zeae slope (slope; $b$ ) in the CPS residue treatment was -0.102 . The rate of decline for residue left on the surface was significantly less $(P=0.001)$ than for buried residues (CP7.5, -0.113 ; CP15, -0.109 ; and MP15, -0.111). In all treatments, the level of colonization of residues by $G$. zeae over time differed during the year. In both 1998 and 1999 during the spring and midsummer months (April to July), the rate of decline of $G$. zeae in residue in all treatments was greater $(P=0.05)$ than during the rest of the year. The lowest rates of decline were obtained during the periods from July 1998 to October 1998 and October 1998 to April 1999.

Although there was a decrease in the number of nodes infested with $G$. zeae over time, the number of nodes infested with Fusarium spp. overall remained greater than $80 \%$. F . graminearum ( $G$. zeae) declined more slowly in residue on the soil surface (Fig. 3A) than in buried residue (Fig. 3B). Other species of Fusarium recovered from the node pieces included F. culmorum (W.m G. Sm.) Sacc., F. sambucinum Fuckel, F. equiseti (Corda) Sacc. sensu Gordon, F. acuminatum Ellis \& Everh. sensu Gordon, F. sporotrichioides Sherb., F. poae (Peck) Wollenweb., F. subglutinans (Wollenweb. \& Reinking) P. E. Nelson, T. A. Tousson \& Marasas comb. nov., $F$. verticillioides (Sacc.) Nirnberg, F. avenaceum (Fr.:Fr.) Sacc., F. semitectum Berk. \& Ravenel, F. oxysporum Schlechtend. emend. W. C. Snyder \& H. N. Hans., and F. solani (Mart.) Appel \& Wollenweb. emend. W. C. Snyder \& H. N. Hans.(Fig. 3). F. equiseti and F. sporotrichioides were recovered at all sampling times and were the most frequently isolated Fusarium spp. other than $F$. graminearum. Although the proportion of nodes from which $F$. graminearum was recovered decreased over time, the proportion of nodes from which $F$. equiseti, $F$. sporotrichioides, $F$. oxysporum, and $F$. solani were recovered increased over time. $F$. culmorum was recovered only at the beginning of the sampling period (April and May 1998) and at a low frequency $(<5 \%)$. F. poae was recovered only in April and September 1998, and also at low frequencies $(<3 \%)$. F. semitectum, $F$. oxysporum, and $F$. solani generally were recovered in greater frequencies from buried residue samples (Fig. 3).

The relationship between decomposition of wheat residue and recovery of $G$. zeae from nodes was highly significant $(r=$ 0.72; $P=0.001$ ) (Fig. 4), indicating that, as residue decomposed, G. zeae was recovered less. Toward the end of the study, especially in treatments where residue was buried, nodes were not recovered from the bags used to determine residue decomposition and biochemical composition, but still were recovered from the bags used for $G$. zeae survival determinations. This generated a few data points where it appears that $G$. zeae was recovered from a dry weight of zero percent (Fig. 4).

Residue supported G. zeae perithecial formation and subsequent production of mature ascospores under the temperature, moisture, and light conditions of this study (Table 1). The data for ascospore recovery was highly variable and did not allow the detection of differences within many of the sampling dates. Except for CPS, all treatments showed a gradual decline in ascospore production within the first year. The rate of decline of ascospore counts from residue infested with $G$. zeae differed significantly $(P=0.05)$ among the treatments over time. In the first year of sampling (October 1997 to September 1998), after the residue had been placed in the field for 11 months, ascospore counts in buried residue declined by less than $50 \%$ of the original counts (October 1997) (Table 1).

During the second year (November 1998 to October 1999), the number of ascospores recovered per gram of residue from each treatment fluctuated considerably. Comparisons could not be made between the number of ascospores from the first and second years due to changes in recovery methods. Residue remaining following the analysis of the April 1998 sampling

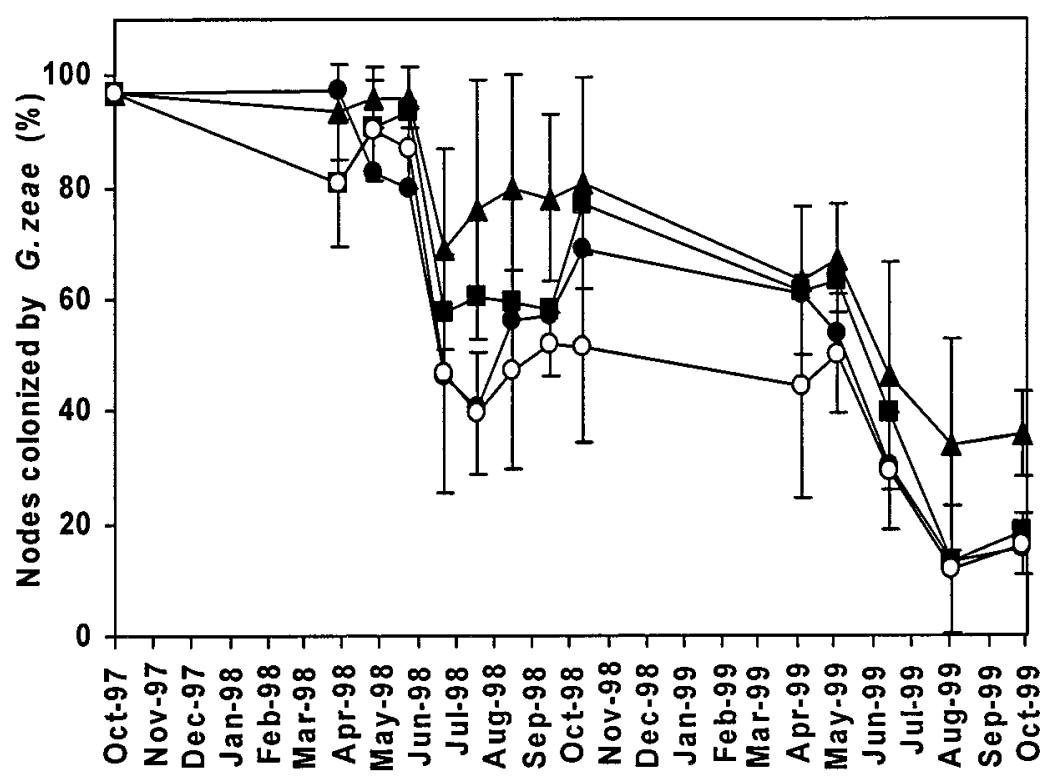

Time (months)

Fig. 2. Percentage of wheat nodes from which Gibberella zeae was recovered in four tillage and residue placement treatments $(\boldsymbol{\Lambda}$, chisel plow with residue on the soil surface; $\mathbf{\square}$, chisel plow with residue buried at $7.5 \mathrm{~cm}$; $\boldsymbol{O}$, chisel plow with residue buried at $15 \mathrm{~cm}$; and $\bigcirc$, moldboard plow with residue buried at $15 \mathrm{~cm}$ ) over 24 months. Residue was placed in the field in October 1997. Values represent means of five replicates, except for August 1999, where the chisel plow at $7.5 \mathrm{~cm}$ and moldboard plow at $15 \mathrm{~cm}$ treatments had four replicates, and October 1999, where the chisel plow at $7.5 \mathrm{~cm}$, chisel plow at $15 \mathrm{~cm}$, and moldboard plow at $15 \mathrm{~cm}$ treatments had three replicates. Vertical bars represent standard deviations of the means. 


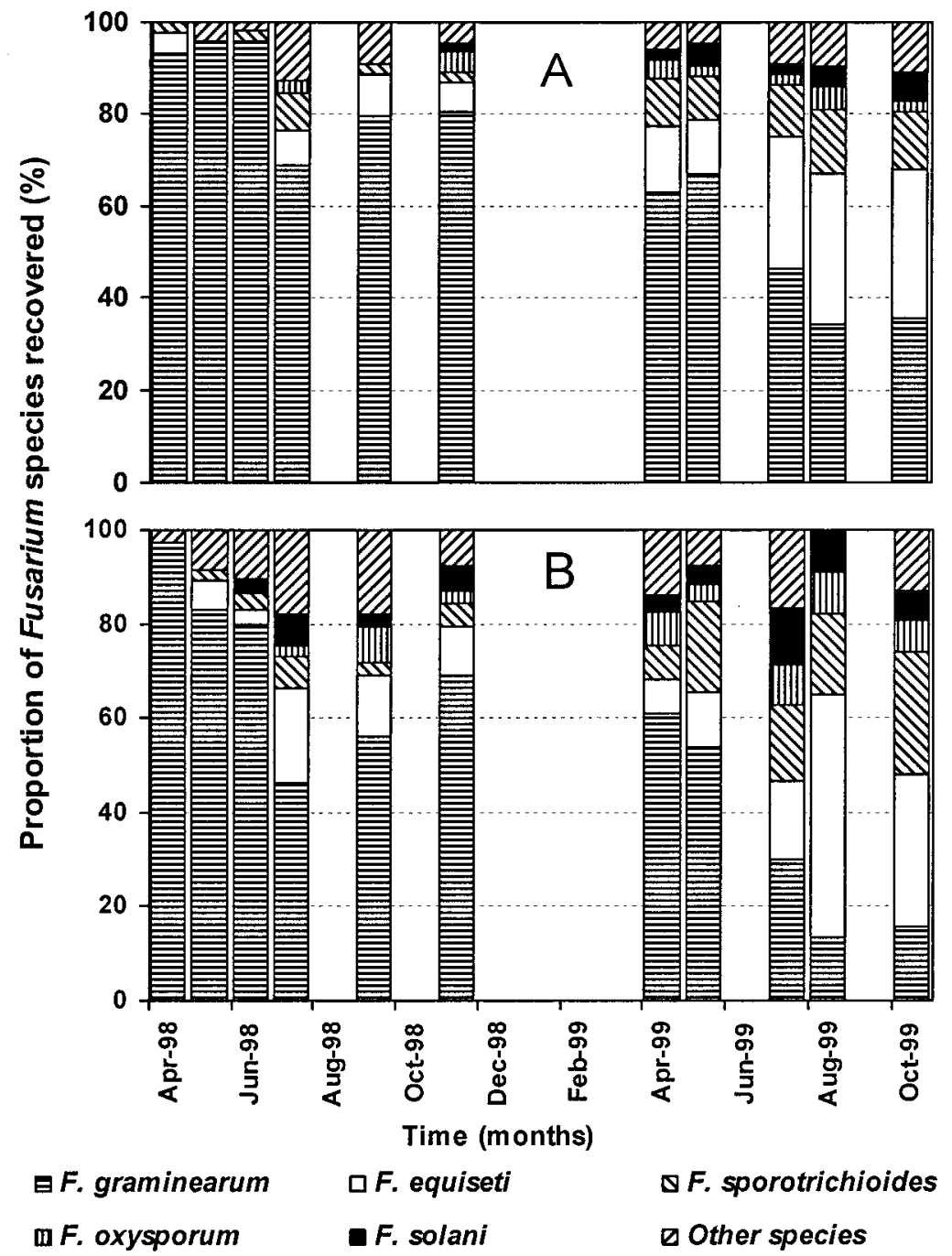

Fig. 3. Proportion of Fusarium spp. (F. graminearum [Gibberella zeae], F. equiseti, F. sporotrichioides, F. oxysporum, F. solani, and others) recovered from wheat node pieces placed in the field in October 1997 and collected from April 1998 to October 1999. Data is shown for two tillage and residue placement treatments: A, chisel-plowed residues left on the soil surface (CPS) and B, chisel-plowed residues buried at $15 \mathrm{~cm}$ (CP15). Values represent means of five replicates. Other Fusarium spp. included F. culmorum, F. sambucinum, F. acuminatum, F. poae, F. subglutinans, F. verticillioides, F. avenaceum, and F. semitectum.

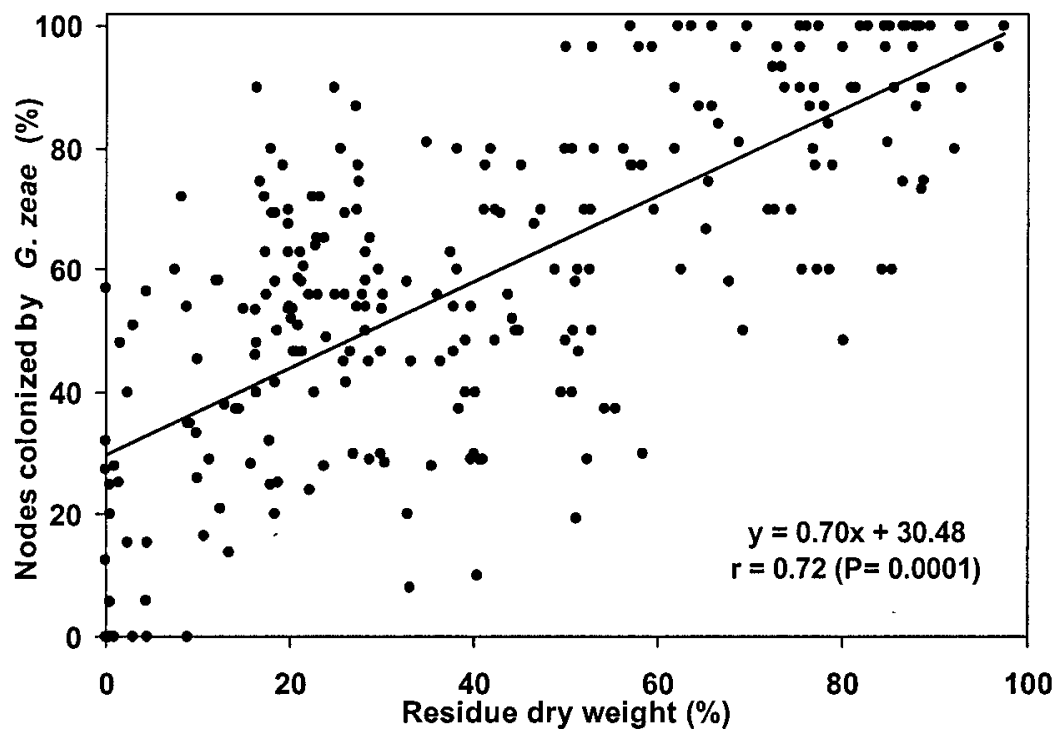

Fig. 4. Relationship between wheat residue dry weight (\%) recovered from four tillage and residue placement treatments and the colonization of nodes by Gibberella zeae (\%). was retained and analyzed with the dilution method in order to have a reference (Table 1). In 1999, the number of ascospores recovered per gram of residue was significantly different among treatments $(P$ $=0.0339)$ and among sampling dates $(P=$ $0.0001)$. The highest numbers of ascospores were recorded in the second year of the study from residue at the soil surface (CPS) and from residue buried at $15 \mathrm{~cm}$ in the moldboard plowed plots (MP15) in May 1999. In both years, the maximum ascospore production generally was observed in the April and May samplings. After the residue had been in the field for 22 to 24 months, the number of ascospores recovered was greatly reduced (Table 1).

For the first year of sampling (April to September of 1998), the relationship between recovery of G. zeae from nodes and recovery of ascospores on silicone-greased slides was significant $(P=0.04$, correlation coefficient $=0.52$ ). The relationship between recovery of $G$. zeae from nodes and recovery of ascospores by dilution in the second year of the study (November 1998 to October 1999) was not significant.

The isolates of G. zeae recovered from the residue sampled in August 1999 were tested for pathogenicity. All isolates induced disease on wheat spikes of the susceptible wheat cv. Norm. Disease symptoms 1 to 3 days after inoculation were water-soaked, brown spots on the inoculated spikelets. Symptoms spread during the following 2 weeks. Salmon-pink hyphae, sporodochia, and premature bleaching could be observed on the symptomatic glumes 14 days after inoculation. Control spikes injected with sterile water did not show disease symptoms. The range in aggressiveness among recovered isolates of $G$. zeae, as indicated by the range in disease severities (percentage of symptomatic spikelets per spike), was 40 to $94 \%$ at 14 days after inoculation. Isolate Butte86/ADA-11 had 56\% severity.

\section{DISCUSSION}

Results of this study indicate that $G$. zeae can survive and produce ascospores on wheat residue in the field for at least 2 years after harvest. This indicates that wheat residue can be a long-term source of $G$. zeae inoculum. The reduction in the colonization of residues by $G$. zeae over the 2 years of this study was positively correlated to the reduction in the amount of residue by decomposition. Burial of residue contributes to greater microbial activity that accelerates decomposition (34). Reduced recovery of G. zeae following the burial of Fusarium-infested residues is in agreement with the findings of earlier studies $(7,22,40)$.

G. zeae was the most prevalent Fusarium $\mathrm{sp}$. isolated from residue during the first year of this study. Recovery of G. zeae declined over time in all residue placement treatments, whereas the proportion of other 
Fusarium spp. increased. This suggests that species of Fusarium other than $G$. zeae, whether already colonizing the residue, such as $F$. poae, or present in the adjacent soil, like $F$. oxysporum and $F$. solani, may be more effective colonizers of partially decomposed wheat residues. G. zeae has the ability to rapidly colonize senescing plant tissue and likely benefits from the ability to colonize wheat residues as a pathogen prior to the arrival of saprophytes. Species such as $F$. equiseti, $F$. oxysporum, F. solani, and F. sporotrichioides, which increased in prevalence over time in this study, have been reported to have a greater saprophytic ability than $F$. graminearum $(6,16,21,32)$. F e equiseti, $F$. oxysporum, $F$. solani, and F. sporotrichioides are highly competent saprophytes in the residue and soil environment (16,33), but not aggressive pathogens of small grains and, thus, are unlikely to depend on pathogenesis to survive.

F. equiseti exists both free in the soil and in association with organic residues, including wheat $(6,8)$, whereas both $F$. oxysporum and $F$. solani form chlamydospores and are considered well adapted to long-term survival in soil $(5,6,31) . F$. oxysporum, $F$. solani, and $F$. equiseti have been reported as dominant species in prairie and corn field soils in southern Minnesota (45). G. zeae is the most prevalent Fusarium sp. recovered from wheat spikes at anthesis, although other species, such as $F$. poae, $F$. verticillioides, $F$. sporotrichioides, and F. equiseti, also may be readily recovered (26).

Soil moisture and soil temperature can affect the rate of residue decomposition and the subsequent survival of the pathogens, as reported by Parr and Papendick (34). In all treatments of this study, the survival of G. zeae decreased most rapidly between April and July each year. Decline in the survival of G. zeae observed during summer months may correspond to a period of rapid residue decomposition observed under warm, wet soil conditions. Conversely, little decomposition occurred during winter, when soil temperatures limited microbial degradation of residues. These conditions also may favor microorganisms that compete with G. zeae. Soil moisture and temperature also have been reported to alter the inoculum potential of $G$. zeae and the populations of fungal species common in wheat residues (16).

Biochemical composition of residue may have affected the rate of residue decomposition. The rate of residue decomposition is known to decrease as the carbon:nitrogen ratio increases (24). Wheat residues generally have a higher carbon:nitrogen ratio at harvest than many other crops (41). Due to the low levels of nitrogen and other nutrients essential for microbial activity, the decomposition of wheat residue tends to be slower than other crops (34). The addition of nitrogen fertilizer has been reported to accelerate the decomposition of wheat residue $(16,42)$. Preliminary results (A. Sims, unpublished data) in the comparison between the decomposition rates of nitrogen-fertilized and nonfertilized wheat residues have shown decomposition to be slightly faster in fertilized than in nonfertilized treatments. How fertilization and other practices influence residue decomposition and impact the survival of $G$. zeae needs further investigation.

The biochemical composition of residues likely may influence the survival of G. zeae and the frequency by which the different Fusarium spp. are recovered from residues. Initial colonization of plant residues by fungi is reported to involve growth on simple water-soluble components $(16,18)$. In our study, the water-soluble fraction represented about 8 to $10 \%$ of residue weight in treatments at the initiation of the experiment. The soluble fraction decreased more rapidly over time in comparison with other residue components, and represented an even smaller fraction in buried residue treatments. Differential reduction in the water-soluble fraction of residues may explain, in part, the greater colonization by G. zeae of surface residue compared with buried residues. Following the utilization of soluble carbohydrates, hemicellulose and cellulose components of residues generally are used as carbon and energy sources by fungi $(18,33)$. Lignin represented a large proportion of the residue components at later stages in this study. Lignin is not readily used by all fungi (18) and its higher proportion in residues may have influenced which microorganisms were isolated toward the end of this study.

Wheat residue from which $F$. graminearum was isolated supported development of perithecia and subsequent release of mature ascospores. During the first year of the study, ascospore production from sampled residue was relatively large; although, across treatments, the number declined over time within the first year. In both years, maximum ascospore production occurred in April or May, a time of year when perithecia commonly are observed in North America (22,39). It seems likely that perithecia initiation would start in the field by May, allowing perithecia to release mature ascospores by the time grasses, including cereal crops, begin flowering. Results of this study confirm that G. zeae has the potential to produce inoculum capable of infecting wheat plants until the residue is completely degraded, as reported previously by Khonga and Sutton (22). Even when ascospores represent the predominant form of primary FHB inoculum in North America (39), conidia recovered from wheat spikes during anthesis indicate that conidia also may play a role in the primary disease cycle (26) and should be considered in future studies of inoculum production from residues.

Residues located on the soil surface, which decomposed more slowly compared with buried residues, supported the survival of $G$. zeae for significantly longer periods of time. This suggests that, under conservation tillage management practices, where significant amounts of residue remain on the soil surface, G. zeae would be more likely to survive and produce inoculum capable of infecting wheat crops com-

Table 1. Number of ascospores of Gibberella zeae produced on wheat residue pieces recovered from four tillage and residue placement treatments sampled from April 1998 to October 1999

\begin{tabular}{lccccc}
\hline & \multicolumn{4}{c}{ Ascospores/stems or nodes $^{\mathbf{a}}$} & \\
\cline { 2 - 4 } Sampling date & CPS & CP7.5 & CP15 & MP15 & LSD $^{\mathbf{b}}$ \\
\hline Slide method & & & & & \\
$\quad$ April 1998 & 54.9 & 97.8 & 48.4 & 56.1 & $\mathrm{~ns}$ \\
May 1998 & 50.3 & 72.2 & 27.1 & 33.1 & 34.3 \\
July 1998 & 38.6 & 47.5 & 20.0 & 23.3 & 25.2 \\
September 1998 & 49.3 & 57.8 & 30.9 & 27.0 & $\mathrm{~ns}$ \\
LSD & $\mathrm{ns}$ & 38.2 & 26.7 & 29.8 & $\ldots$ \\
Dilution method & & & & & \\
April 1998 & 35.6 & 19.3 & 19.1 & 22.4 & $\mathrm{~ns}$ \\
November 1998 & 10.2 & 10.0 & 16.4 & 11.8 & $\mathrm{~ns}$ \\
April 1999 & 33.8 & 71.5 & 30.4 & 6.9 & $\mathrm{~ns}$ \\
May 1999 & 104.0 & 40.0 & 21.0 & 105.0 & 58.3 \\
July 1999 & 41.6 & 18.0 & 13.6 & 8.9 & 30.2 \\
August 1999 & 8.0 & 3.1 & 1.8 & $\mathrm{nd}$ & 6.0 \\
October 1999 & 11.6 & $\mathrm{nd}$ & $\mathrm{nd}$ & $\mathrm{nd}$ & $\ldots$ \\
LSD & 46.8 & 60.6 & $\mathrm{~ns}$ & 17.0 & $\ldots$ \\
\hline
\end{tabular}

${ }^{a}$ At the time of trial establishment (October 1997), 72 ascospores $/ \mathrm{cm}^{2}$ were recovered from the residue, using the slide method; $\mathrm{nd}=$ not determined due to insufficient sample size; ns $=$ no significant difference. Tillage and residue placement treatments were CPS $=$ chisel plowed with residue on the surface, CP7.5 = chisel plowed with residue buried at 7.5 to $10.0 \mathrm{~cm}, \mathrm{CP} 15=$ chisel plowed with residue buried at 15 to $20 \mathrm{~cm}$, and MP15 = moldboard plowed with residue buried at 15 to $20 \mathrm{~cm}$.

${ }^{\mathrm{b}} \mathrm{LSD}=$ least significant difference $(P=0.05)$.

c Ascospore numbers determined using the slide method are expressed as spores $/ \mathrm{cm}^{2}$.

${ }^{\mathrm{d}}$ Ascospore numbers determined using the dilution method are expressed as thousands of spores per gram of residue. 
pared with tillage operations that incorporate residue into the soil. Although tillage may aid disease control, Miller et al. (29) suggested that residue management practices alone may not be sufficient to control FHB because airborne inoculum can move from adjacent areas, including neighboring fields with abundant surface residue. However, tillage to reduce inoculum may be practical if it is implemented widely or in combination with other disease control practices.

The results of this study demonstrate that the resurfacing of previously buried Fusarium-infested residues during tillage operations may expose these residues to conditions favorable for the production of perithecia and ascospores. Thus, the residues of cereals, irrespective of their age, are likely to be a source of FHB inoculum. Recognizing that $G$. zeae survives in wheat residue for at least 2 years is important, and should be noted when decisions on crop rotations are considered for FHB management. Crop rotations into nonhost species may provide a degree of control of FHB. In the Red River Valley, crop rotations that include a host of G. zeae only once every 3 years may aid in reducing the in-field inoculum under reduced tillage systems. Nonhost crops that can be incorporated into rotations in Minnesota include sunflower, edible beans, canola, and forage legumes.

Additional studies to evaluate the effect of cultural practices on FHB should include the examination of long-term rotations with nonhost crops and the use of tillage practices that accelerate residue breakdown, including chopping and distribution of residue, nitrogen applications, green manures, residue burning, and application of chemicals such as acetic acid, which have been reported to reduce perithecial production on crop residues (23). Biological control of G. zeae in residues also could be examined as a control option. A better understanding of the factors that influence the survival and inoculum production of G. zeae in host residues likely will aid growers in implementing the appropriate practices for the management of FHB.

\section{ACKNOWLEDGMENTS}

We thank C. K. Evans, A. Elakkad, K. Hoff, L. Miller, M. Morelli, C. Newby, and C. Schraut for their technical assistance.

\section{LITERATURE CITED}

1. Analytical Software. 1998. Statistix for Windows. User's Manual. Borlan International Inc., Tallahassee, FL.

2. Andersen, A. L. 1948. The development of Gibberella zeae headblight of wheat. Phytopathology 38:595-611.

3. Anonymous. 1991. Conservation in the 1990 Farm Bill. United States Department of Agriculture, FACTA 2.

4. Bai, G., and Shaner, G. 1994. Scab of wheat: prospects for control. Plant Dis. 78:760-766.

5. Booth, C. 1971. The Genus Fusarium. Farn- ham Royal, Commonwealth Agricultural Bureau, Commonwealth Mycological Institute, Kew, UK.

6. Burgess, L. W. 1981. General ecology of Fusaria. Pages 225-235 in: Fusarium: Diseases, Biology and Taxonomy. P. E. Nelson, T. A. Tousson, and R. J. Cook, eds. The Pennsylvania State University Press, University Park.

7. Burgess, L. W., and Griffin, D. M. 1968. The recovery of Gibberella zeae from wheat straws. Aust. J. Exp. Agric. Anim. Husb. 8:364-370.

8. Burgess, L. W., Summerell, B. A., Bullock, S., Gott, K. P., and Backhouse, D. 1994. Laboratory Manual for Fusarium Research. Third ed. University of Sydney, Sydney, Australia.

9. Cook, R. J., and Baker, K. F. 1983. The Nature and Practice of Biological Control of Plant Pathogens. The American Phytopathological Society Press, St. Paul, MN

10. Cook, R. J., Boosalis, M. G., and Doupnik, B. 1978. Influence of crop residues on plant diseases. Pages 147-163 in: Crop Residue Management Systems. W. R. Oschwald, ed. ASA Spec. Publ. 31. American Society of Agronomy, Madison, WI.

11. Dill-Macky, R. 1996. Fusarium head blight: recent epidemics and research efforts in the Upper Midwest of the United States. Pages 1-6 in: Fusarium Head Scab: Global Status and Future Prospects. H. J. Dubin, L. Gilchrist, J. Reeves, and A. McNab, eds. CIMMYT, Mexico, D.F.

12. Dill-Macky, R., and Jones, R. 2000. The effect of previous crop residues and tillage on Fusarium head blight of wheat. Plant Dis. 84:71-76.

13. Evans, C. K., Xie, W., Dill-Macky, R., and Mirocha, C. J. 2000. Biosynthesis of deoxynivalenol in spikelets of barley inoculated with macroconidia of Fusarium graminearum. Plant Dis. 84:654-660.

14. Fernando, W. G. D., Paulitz, T. C., Seaman, W. L., Dutilleul, P., and Miller, J. D. 1997. Head blight gradients caused by Gibberella zeae from area sources of inoculum in wheat field plots. Phytopathology 87:414-421.

15. Fischer, N. L., Burgess, L. W. Tousson, T. A., and Nelson, P. E. 1982. Carnation leaves as a substrate for preserving cultures of Fusarium species. Phytopathology 72:151-153.

16. Garret, S. D. 1970. Pathogenic Root-Infecting Fungi. Cambridge University Press, Cambridge.

17. Harper, S. H. T., and Lynch, J. M. 1981. The chemical components and decomposition of wheat straw leaves, internodes and nodes. J. Sci. Food Agric. 32:1057-1062.

18. Harper, S. H. T., and Lynch, J. M. 1985. Colonization and decomposition of straw by fungi. Trans. Br. Mycol. Soc. 85:655-661.

19. Hoffer, G. N., Johnson, A. G., and Atanasoff, D. 1918. Corn-rootrot and wheatscab. J. Agric. Res. 3:611-612.

20. Holbert, J. R., Trost, J. F., and Hoffer, G. N. 1919. Wheat scabs as affected by systems of rotation. Phytopathology 9:45-47.

21. Jamieson, A. R. 1985. Aggressiveness and saprophytic ability in species of Fusarium associated with wheat. Ph.D. thesis. University of Guelph, Guelph, Canada.

22. Khonga, E. B., and Sutton, J. C. 1988. Inoculum production and survival of Gibberella zeae in maize and wheat residues. Can. J. Plant Pathol. 10:232-239.

23. Khonga, E. B., and Sutton, J. C. 1991. Effects of acetic acid, propionic acid and urea on inoculum production by Gibberella zeae in maize and wheat residues. Mycol. Res. 95:409-412.

24. Knapp, E. B., Elliot, L. F., and Campbell, G. S. 1983. Carbon, nitrogen and microbial biomass interrelationships during the decomposition of wheat straw: a mechanistic simulation model. Soil Biol. Biochem. 15:455-461.

25. Large, E. C. 1954. Growth stages in cereals Illustrations of the Feekes scale. Plant Pathol. 3:128-129.

26. Markell, S. G., and Francl, L. J. 2003. Fusarium head blight inoculum: species prevalence and Gibberella zeae spore type. Plant Dis. 87:814-820.

27. Mathre, D., ed. 1997. Compendium of Barley Diseases. Second ed. The American Phytopatological Society Press, St. Paul, MN.

28. McMullen, M., Jones, R., and Gallenberg, D. 1997. Scab of wheat and barley: A reemerging disease of devastating impact. Plant Dis. 81:1340-1348.

29. Miller, J. D., Culley, J., Fraser, K., Hubbard, S., Meloche, F., Ouellet, T., Seaman, W. L., Seifert, K. A., Turkington, K., and Voldeng, H. 1998. Effect of tillage practice on Fusarium head blight of wheat. Can. J. Plant Pathol. 20:95-103.

30. Nash, S. M., and Snyder, W. C. 1962. Quantitative estimations by plate counts of propagules of the bean root rot Fusarium in field soils. Phytopathology 52:567-572.

31. Nelson, P. A., Tousson, T. A., and Marasas, W. F. O. 1983. Fusarium Species: An Illustrated Manual for Identification. The Pennsylvania State University Press, University Park.

32. Ocamb, C. M. 1991. Ecology of soilborne Fusarium species associated with roots and the rhizosphere of Zea mays. Ph.D. thesis, University of Minnesota, St. Paul.

33. Park, D. 1963. The ecology of soil-borne fungal disease. Annu. Rev. Phytopathology 1:241-258.

34. Parr, J. F., and Papendick, R. I. 1978. Factors affecting the decomposition of crop residues by microorganisms. Pages 101-129 in: Crop Residue Management Systems. W. R. Oschwald, ed. ASA Spec. Publ. 31. American Society of Agronomy, Madison, WI.

35. Parry, D. W., Jenkinson, P., and McLeod, L. 1995. Fusarium ear blight (scab) in small grain cereals-a review. Plant Pathol. 44:207-238.

36. Paulitz, T. C. 1996. Diurnal release of ascospores by Gibberella zeae in inoculated wheat plots. Plant Dis. 80:674-678.

37. Reis, E. M. 1988. Doenças do trigo III. Giberela. [Wheat diseases III. Fusarium head blight]. Segunda ediçâo. Sâo Paulo, Brazil.

38. SAS Institute. 1985. SAS User's Guide. Statistics. Version 5 ed. SAS Institute Inc., Cary, NC.

39. Sutton, J. 1982. Epidemiology of wheat head blight and maize ear rot caused by Fusarium graminearum. Can. J. Plant Pathol. 4:175-209.

40. Sutton, J. C., and Vyn, T. J. 1990. Crop sequences and tillage practices in relation to diseases of winter wheat in Ontario. Can. J. Plant Pathol. 12:358-368

41. Theander, O., and Aman, P. 1984. Anatomical and chemical characteristics. Pages 45-78 in: Straw and Other Fibrous By-Products as Feed. F. Sundstol and E. Owen, eds. Elsevier, Amsterdam.

42. Warren, H. L. and Kommedahl, T. 1973. Fertilization and wheat refuse effects on Fusarium species associated with wheat roots in Minnesota. Phytopathology 63:103-108.

43. Wiese, M. V. 1987. Compendium of Wheat Diseases. Second ed. The American Phytopathological Society Press, St. Paul, MN.

44. Wilcoxson, R. D., Kommedahl, T., Ozmon, E. and Windels, C. E. 1988. Occurrence of Fusarium species in scabby wheat from Minnesota and their pathogenicity to wheat. Phytopathology 78:586-589.

45. Windels, C. E., and Kommedahl, T. 1974. Population differences in indigenous Fusarium species by corn culture of prairie soil. Am. J. Bot. 61:141-145. 